\section{Marijuana Compounds: A Non-Conventional Therapeutic Approach to Epilepsy in Children}

\section{Mariana Babayeva*, Malka Fuzailov, Paulina Rozenfeld and Paramita Basu}

Department of Biomedical and Pharmaceutical Sciences, Touro College of Pharmacy, New York, NY, USA

\begin{abstract}
Epilepsy in children is a complex disease, with a variety of distinct syndromes and many alternative treatment options. Even with a plethora of available treatment options, childhood epilepsies are commonly associated with seizures that are resistant to existing treatment methods. Treatment of pediatric epilepsy is challenging and requires more effective therapy to avoid short-term and long-term neurological disorders.

Marijuana has been used to treat disease since ancient times. Marijuana ingredients Cannabidiol (CBD) and D9-Tetrahydrocannabinol (THC) have created a significant research interest as potential therapy options in epilepsy treatment. THC is the major psychoactive component of marijuana that aids in reducing epileptic seizures. CBD has proven to have anticonvulsant effect not only in experimental models but also in clinical studies. Research studies have provided strong evidence for safety and anticonvulsant properties of medical marijuana. Principal concerns regarding the use of medical marijuana in children include lack of standardization and regulation, imprecise dosing, possible adverse side effects and medication interactions.
\end{abstract}

Keywords: AED; Children; Epilepsy; Medical marijuana

\section{Medical Marijuana}

Marijuana is reported to be the most commonly used illicit substance in the United States, despite the drug's classification as a Schedule 1 Controlled Substance by US Congress in 1970 [1]. The use of marijuana is categorized as such due to its high abuse potential, lack of established safety for use under medical supervision and no

*Corresponding author: Mariana Babayeva, Department of Biomedical and Pharmaceutical Sciences, Touro College of Pharmacy, 230 West 125th Street, Room 433, New York, NY 10027, USA, Tel: 6469814740; Fax: 2126781780; E-mail: mariana.babayeva@touro.edu

Citation: Babayeva M, Fuzailov M, Rozenfeld P, Basu P (2014) Marijuana Compounds: A Non-Conventional Therapeutic Approach to Epilepsy in Children. J Addict Addictv Disord 1: 002.

Received: June 19, 2014; Accepted: September 01, 2014; Published: September 15, 2014

Copyright: ( 2014 Babayeva M, et al., This is an open-access article distributed under the terms of the Creative Commons Attribution License, which permits unrestricted use, distribution, and reproduction in any medium, provided the original author and source are credited. current accepted use for medical purpose. In order for the FDA to approve a compound for medical use, the active ingredients must be of measurable units to properly evaluate quality control. Even with stringent federal provisions, the legalization of medical marijuana has been surrounded by much controversy and debate in many states. There continues to be much speculation amongst policy makers regarding the safety, efficacy and potential outcomes of marijuana [2]. Since 1996, there have been 20 states in addition to Washington DC that passed laws, which allow marijuana to be used to treat certain medical conditions. In 2012, the states of Washington and Colorado passed initiatives legalizing the recreational use of marijuana in adults aged 21 and older [3]. Despite the shift of legalization in some states, the US Government highlights the public health consequences of legalizing marijuana [2]. Legalization would lead to a cascade of negative outcomes that threaten the approach to drug policy. Increasing the availability of the drug would demonstrate a positive correlation in the use of the drug and could result in addiction, respiratory illness, and declines in cognitive processing [3]. Impairments in cognitive function were reported as an 8 point drop in IQ scores between the ages of 18-38 in a New Zealand study [4]. Individuals who began using marijuana during adolescence were unable to have their lost cognitive abilities fully restored in adulthood [5]. At the same time recent research studies have provided strong evidence for therapeutic use of medical marijuana [6-9].

Marijuana is derived from the Cannabis sativa L. plant. The plant species Cannabis sativa L. has two main sub-species, Cannabis indica and Cannabis sativa [10]. Cannabis sativa and Cannabis indica differ fundamentally in their chemical composition, physiological aesthetic, and medical application. Marijuana contains the active chemicals known as cannabinoids. At least 67 phytocannabinoids can be regarded as a natural library of unique compounds. The therapeutic potential of many of these ligands still remains largely unexplored prompting a need for further research [11]. The chemicals responsible for the medicinal effects of marijuana are D9-Tetrahydrocannabinol (THC) and Cannabidiol (CBD) $[12,13]$. Sativa's cannabinoid profile is dominated by high THC levels and low or no CBD $[10,14]$. Indica's chemical composition shows a more balanced mix, with moderate THC levels and higher levels of CBD $[15,16]$.

Cannabinoids are also found endogenously in the body. These chemicals (endocannabinoids) play a role in the endocannabinoid system and aid in regulation of memory, pleasure, concentration, thinking, movement and coordination, sensory and time perception, appetite, and pain [17]. For example, the endocannabinoids synthesized from membrane phospholipids in the cardiovascular tissues can relax coronary and other arteries and decrease cardiac work [18]. Endocannabinoids are largely protective; they decrease tissue damage and arrhythmia in myocardial infarction, and in addition, may reduce progression of atherosclerosis [18].

The endocannabinoids activate two G-protein-coupled cell membrane receptors, consequently named the Cannabinoid type 1 $\left(\mathrm{CB}_{1}\right)$ and type $2\left(\mathrm{CB}_{2}\right)$ receptors [18]. $\mathrm{CB}_{1}$ receptors are located primarily in central and peripheral neurons and $\mathrm{CB}_{2}$ receptors predominantly in immune cells [19]. $\mathrm{CB}_{1}$ receptors are important mediators in signaling pathways and have been identified on both 
glutamatergic and GABAergic neurons [20]. It is believed that one important role of the neuronal $\mathrm{CB}_{1}$ component is to modulate neurotransmitter release in a manner that maintains homeostasis in health and disease by preventing the development of excessive neuronal activity in the central nervous system [19]. Animal models illustrate that activation of $\mathrm{CB}_{1}$ receptor by their endogenous ligands can result in prominent neuroprotective effects and may prevent epileptic seizures [21]. $\mathrm{CB}_{2}$ receptors are closely related to the $\mathrm{CB}_{1}$, and are mainly expressed on $\mathrm{T}$ cells of the immune system, on macrophages and B cells, and in hematopoietic cells [22]. They are also expressed on peripheral nerve terminals where these receptors play a role in antinociception, or the relief of pain [23]. In the brain, they are mainly expressed by microglial cells, where their role remains unclear [24]. While the most likely cellular targets and executors of the $\mathrm{CB}_{2}$ receptor-mediated effects of endocannabinoids or synthetic agonists are the immune and immune-derived cells the number of other potential cellular targets is expanding, now including endothelial and smooth muscle cells, fibroblasts of various origins, cardiomyocytes, and certain neuronal elements of the peripheral or central nervous systems $[25,26]$.

\section{Therapeutic Uses of Marijuana}

Cannabis has been used to treat disease since ancient times. Out of the two major therapeutically active components of marijuana, THC is the major psychoactive ingredient, acting primarily upon the central nervous system where it affects brain function. CBD is the major non-psychoactive ingredient in cannabis and appears to relieve convulsion, inflammation, anxiety, and nausea. Both compounds have anticonvulsant properties. In addition, CBD produces neuroprotective and anti-inflammatory effects, and it is well tolerated in humans [27].

Better understanding of cannabinoid pharmacology and the endocannabinoid system has led to the approval of pharmaceutical cannabinoids that target specific patient populations. Since the 90s, a pill form of marijuana has been prescribed to treat wasting syndrome in AIDS patients [28]. Nausea, appetite loss, pain, and anxiety are afflictions of wasting, all of which can be mitigated by marijuana [29]. Moreover, while multiple reviews have concluded immunosuppressive consequences of cannabis use, recent findings suggest marijuana may even help combat the AIDS. The new study has shown that chronic intake of marijuana can protect critical immune tissue from the damaging effects of HIV infection [30]. At present, AIDS and cancer patients utilize various drugs containing synthetic THC such as Dronabinolor Nabilone [31-33]. The drugs are used to decrease marijuana withdrawal symptoms as well as to increase appetite and prevent chemotherapy related nausea and vomiting [28,34,35].

Study data published by GW Pharmaceuticals reported positive results of THC: CBD treatment in patients affected by Multiple Sclerosis (MS), spinal cord injury, neuropathic pain or peripheral neuropathy. This report also confirmed excellent safety profiles for cannabis-based medicines [36]. At present, a combination of both cannabinoids THC and CBD are used therapeutically in Sativex to alleviate pain symptoms in multiple sclerosis [37,38]. Sativex was approved in UK, Spain, Czech Republic, Germany, Denmark, Sweden, Italy and Austria. In Canada Sativex has been approved for the treatment of multiple sclerosis spasticity and also for advanced cancer pain [39].

Clinical trials are currently underway in San Francisco, CA investigating the effects of a pure cannabinoid drug called Epidiolex.
The trial will evaluate the safety and tolerability of this drug in the treatment of severe and debilitating seizures in children non-responsive to traditional anti-epileptic drug regimens [38].

While some studies have found that some percentage of the general population using cannabis for therapeutic purposes may develop a dependence on this substance [40], a growing amount of research on cannabis-related substitution suggests that for many patients cannabis is not only an effective medicine, but also a potential exit drug to problematic substance use. It was reported that subjects frequently use cannabis as a substitute for alcohol, illicit substances, and prescription drugs [41].

Even with promising results promoting the therapeutic applications of marijuana, federal barriers and public health concerns regarding marijuana's potential risk to cause addiction and dependence, increase co-morbidities, cardiopulmonary effects and overall mental health still exist [42]. Other negative effects may include paranoia and psychosis when consumed in high doses $[43,44]$. According to studies focused on cannabis dependence, approximately 300,000 patient admissions into substance abuse treatment clinics are predominantly marijuana-related problems, exceeding the rates of heroin and cocaine [35].

\section{Epilepsy and Traditional Therapy}

Epilepsy is a neurological disorder characterized by recurrent unprovoked seizures and is recognized as one of the most common nervous system disorders [45]. According to the Epilepsy Foundation of America, approximately 3 million Americans are affected with epilepsy [46], and up to 50,000 Americans die each year from seizures and related causes [47]. 30\% of the patients diagnosed with epilepsy are children. Costs of the disease result in significant financial impact of $\$ 15.5$ billion annually [48]. Despite current pharmacologic and medical treatment, more than one-third of individuals with epilepsy continue to experience seizures [49].

Children epilepsy may result from various etiologies but the majority of epilepsy cases are of idiopathic nature [50]. Numerous medical conditions can cause epilepsy, in addition to genetic mutations and traumatic injury to the brain. Certain patient populations that are at greater risk for developing seizures and epilepsy include those with mental retardation, cerebral palsy, head injuries, or strokes [51]. Seizures are triggered when electrical patterns in the cerebral cortex are simultaneously activated, leading to hyperexcitbaility of neuronal activity and disruptions in homeostatic mechanisms $[52,53]$. The outcome of a seizure depends largely on the location in the brain where the electrical imbalance occurred. Epileptic seizures can be divided into two broad categories of generalized seizures, which include absence, atonic, tonic-clonic, myoclonic seizures, as well as partial seizures.

The primary method to control seizures consists of treatment regimens containing Anti-Epileptic Drugs (AEDs). AEDs must be carefully selected depending on the type of seizure, as well as the safety and efficacy of the medication in the specific patient. Currently, first-line AED medications include phenytoin (Dilantin), carbamazepine (Tegretol), and divalproex sodium (Depakote). Other treatment options include the use of anticonvulsants, surgical procedures to remove damaged neural tissue in certain candidates, Vagal Nerve Stimulation (VNS), ketogenic diets and lifestyle changes [53-57]. Unfortunately, the treatments are not effective in more than $30 \%$ of patients with epilepsy [58]. 
Moreover, AED therapy is known to be associated with numerous drug-drug interactions. Most of the anti-epileptic drugs are inducers or inhibitors of metabolic enzymes. Induction of hepatic enzymes by AEDs such as carbamazepine, phenytoin and phenobarbital may cause increased metabolism and decreased therapeutic effects of many other drugs, such as steroid hormones or warfarin. Felbamate and valproate are metabolic inhibitors and can increase pharmacological effects of other hepatically metabolized drugs. Conversely, other drugs (e.g., erythromycin or fluoxetine, potent inhibitors) may inhibit the metabolism of AEDs. It is sometimes difficult to predict what type of interaction will occur when two AEDs or an AED and another drug are used together [54].

\section{Epilepsy in Children}

Epilepsy can affect children of all races and ethnic backgrounds. Approximately 326,000 American children under the age of 15 are diagnosed with epilepsy and the incidence amongst the youth is estimated at 200,000 cases diagnosed annually [59].

Epilepsy in children is a complex disease, with a variety of distinct syndromes and many alternative treatment options and outcomes. The disease burden can affect children differently; as some respond favorably to medication treatments and others struggle with epilepsy as a lifelong challenge. Even with a plethora of available treatment options, childhood epilepsies beginning in early years of life are commonly associated with seizures that are resistant to existing treatment methods. Multiple ongoing seizures in early childhood are more likely to attribute to long term deficits in cognition, behavior, and motor areas, depending on the extent of damage to the brain [45]. Managing pediatric epilepsy syndromes is tough. A comprehensive treatment plan includes pharmacologic, non-pharmacologic, and surgical options [60]. Resistance to epilepsy regimens have created a major challenge in treatment, especially in epileptic disorders such as Dravet syndrome, Lennox-Gastaut syndrome, Doose and West syndromes [61].

Dravet syndrome is classified as a severe form of epilepsy that results from a genetic mutation in the alpha-subunit of the sodium channel SCN1A [62-64]. In some cases of Dravet syndrome, genetic mutations cause the inactivation of one copy of the gene, known as haplo-insufficiency, in which there is only one functional copy. An estimated $90 \%$ of Dravet syndrome cases are a result of 'de novo' mutations in the child $[65,66]$. This syndrome typically begins in the first year of infancy and can present in children of otherwise normal development prior to seizure onset. Seizures can be generalized, focal or tonic-clonic [67]. Dravet syndrome is a highly pharmaco-resistant form of epilepsy. Valproate and benzodiazepines are the first-line treatment but are usually insufficient therapeutic options [68]. Individuals experiencing acute seizures are treated with benzodiazepines, such as clonazepam, lorazepam and midazolam. Maintenance treatment for chronic seizures associated with Dravet syndrome most commonly include levetiracetam and sodium valproate often in combination with topiramate or stiripentol $[69,70]$. Certain AEDs can aggravate seizures and should be avoided in patients with Dravet syndrome. These AEDs include carbamazepine, lamotrigine, diphenylhydantoine, high doses of intravenous phenobarbital and vigabatrin [61,71]. Worsening of symptoms was noted during administration of these medications, which persisted even after their washout period was completed. Infants being treated for status epilepticus with phenobarbital developed cerebral atrophy with dramatic neurological worsening [71,72]. Managing of Dravet syndrome is challenging and often unsuccessful [73].
Lennox-Gastaut Syndrome (LGS) is a severe, chronic, epileptic encephalopathy, primarily with childhood onset, [74-76]. LGS syndrome begins in childhood (between 1 and 8 years of age), worsens during latency, and persists frequently into adulthood. The syndrome is refractory to anti-epileptic medications, and results in cognitive decline and behavioral problems in affected individuals. Seizure types consist primarily of axial tonic, atonic, and atypical absence; nocturnal tonic seizures are the most common seizure pattern in this population [77]. Lennox-Gastaut syndrome has a heterogeneous etiology. Recent findings suggest that CHD2 and SCN1A mutations are important in the etiological spectrum of LGS disorder $[78,79]$. Lennox-Gastaut syndrome may be considered secondary network epilepsy because the unifying epileptic manifestations of the disorder, which reflect network dysfunction, rather than the specific initiating process [80]. Treatment options for Lennox-Gastaut syndrome have been less than optimal. The choices of AEDs are based on the seizure types; routinely, two or more the classic drugs, valproate and clonazepam are recommended [81].

In recent years, several drugs have been tested and approved for the treatment of this syndrome; these include felbamate, lamotrigine, topiramate, and rufinamide. The long-term outcome does not appear to be any better with the newer AEDs, than when using earlier prescribed AEDs or polytherapy [77]. Long-term outcome of these patients relative to seizure control and cognition is poor. Most develop moderate intellectual disability within a few years of onset of the syndrome. Many others develop behavioral problems with inattention, hyperactivity and aggression [77].

Doose syndrome, Myoclonic-Astatic Epilepsy (MAE) is characterized by myoclonus, myoclonic-astatic, or astatic seizures in childhood. There is a partial overlap with other pediatric epileptic syndromes, such as Dravet and Lennox-Gastaut [82]. The actual genetic determinants of MAE still remain unknown. Although initially thought to be within the same spectrum as severe myoclonic epilepsy of infancy, the exclusion of SCN1A mutations in non-generalized epilepsy with febrile seizures MAE cases has confirmed the genetic distinction of MAE [83]. Treatment of MAE includes AEDs, ketogenic diet and Adrenocorticotropic Hormone (ACTH) [84]. The course of MAE is highly variable with regard to seizure outcome (complete remission in some cases, persistent epilepsy in others) and normal or delayed cognitive development $[85,86]$.

West Syndrome (WS) is a rare age-dependent epileptic encephalopathy characterized by epileptic spasms, specific EEG pattern (hypsarrhythmia), and psychomotor retardation. West Syndrome typically begins in the first year of life, usually between 3 and 8 months [87]. Epileptic spasms, tonic, atonic, generalized tonic-clonic, and myoclonic seizures are common. Prenatal and perinatal brain injury, metabolic, degenerative disorders, and neurocutaneous disorders and cerebral malformations are frequently identified in these patients [45]. Pharmacologic agents used to treat WS include the benzodiazepines, valproate and corticosteroids or corticotrophin, vigabatrin. West Syndrome associated with focal cortical dysplasia has been treated by resective surgery [88]. Neurodevelopment is normal in only $10-15 \%$ of affected patients [89].

Childhood epilepsies are commonly associated with seizures that are resistant to existing therapies. Treatment of pediatric epilepsy is challenging and requires more effective therapy to avoid short-term and long-term neurological disorders. 


\section{Mechanism of Action of Cannabinoid Compounds}

THC binds to $\mathrm{CB}_{1}$ and $\mathrm{CB}_{2}$ receptors, to exert its effects. The endogenous ligands for these receptors are the Endocannabinoids Anandamide (AEA) and 2-Arachidonoylglycerol (2-AG), which are both cannabinoid compounds made by the body and have protective effects. THC serves as a partial agonist at the $\mathrm{CB}_{1}$ receptors, which are located mainly in the brain, and are identified as both inhibitory GABA and excitatory glutamatergic neurons. THC it is also a partial agonist of $\mathrm{CB}_{2}$ receptors, primarily found in immune and hemato poietic cells.

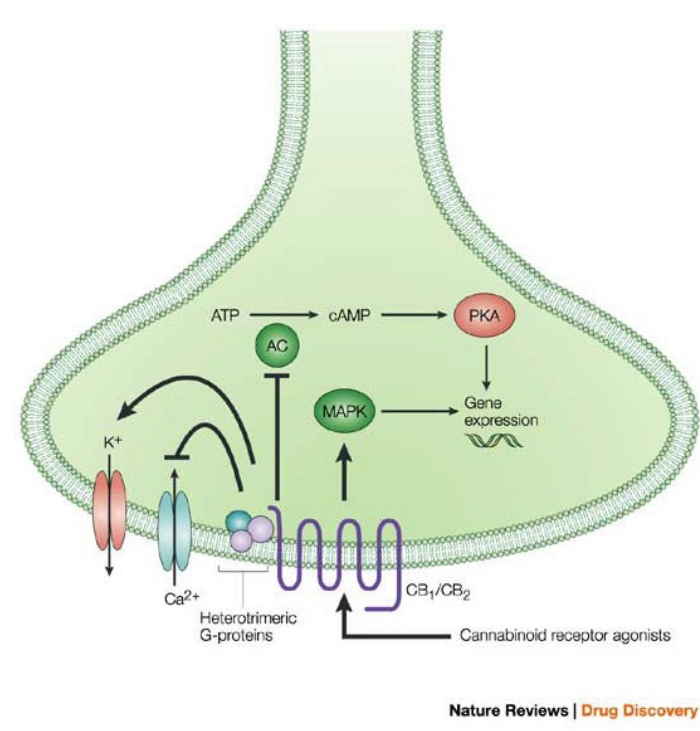

Figure 1: Major signalling pathways associated with cannabinoid receptor activation by agonists.

Reproduced with permission from (Vincenzo DiMarzo, Maurizio Bifulco \& Luciano De Petrocillis. 2004. The endocannabinoid system and its therapeutic exploitation. Nature Reviews Drug Discovery).

Activation of both cannabinoid $\mathrm{CB}_{1}$ and $\mathrm{CB}_{2}$ receptors, and the subsequent stimulation of $\mathrm{G}_{\mathrm{i} / \mathrm{o}}$ heterotrimeric proteins, is well known to be coupled to inhibition of Adenylate Cyclase (AC) with corresponding inactivation of the Protein Kinase A (PKA) phosphorylation pathway, or to stimulation of Mitogen-Activated Protein Kinase (MAPK). These intracellular events lead to, among other effects, the regulation of expression of several genes. However, more complex protein phosphorylation cascades-specifically, those involving phosphoinositide-3-kinase and protein kinase B- are also proposed to be triggered by $\mathrm{CB}_{1}$ receptors. Furthermore, stimulation, rather than inhibition, of $A C$ by $C_{1}$, but not $C_{2}$, receptors, via $G_{s}$ proteins, has also been described occasionally. $\mathrm{CB}_{1}^{-}$, but not $\mathrm{CB}_{2}{ }^{2}$, receptor stimulation of $\mathrm{G}_{\mathrm{i} / \mathrm{o}}$ proteins is also directly coupled to inhibition of voltage-activated $\mathrm{Ca}^{2+}$ channels and stimulation of inwardly $\mathrm{K}^{+}$channels in neurons, with subsequent inhibition of neurotransmitter release. The choice between which of these pathways is modulated by cannabinoid receptor activation also depends on the type of agonist-cAMP, cyclic AMP.

Due to the structural similarity of THC to the endogenous cannabinoid AE, many therapeutic advantages of THC (which mimic the effects of $\mathrm{AE}$ ) have been identified, such as lowering ocular pressure, inhibiting smooth muscle contractions, and increasing appetite [90]. When smoked, THC is rapidly absorbed from the lungs and into the bloodstream and has an effect on the cannabinoid receptors. The central nervous system and specific areas of the brain contain the highest concentration of cannabinoid receptors and therefore the chemicals found in marijuana will create an over-excitation of the endocannabinoid system [91]. This will result in altered perceptions, pleasure and mood.

Although THC is the main psychoactive agent found in marijuana, other cannabinoids contribute to the plant's medicinal properties [7]. Studies in experimental models and humans have suggested anti-inflammatory, neuroprotective, anxiolytic, and antipsychotic properties of chemicals extracted from marijuana $[7,15,19,92,93]$.

Unlike THC, $\mathrm{CBD}$ has little affinity for $\mathrm{CB}_{1}$ and $\mathrm{CB}_{2}$ receptors but acts as an indirect antagonist of cannabinoid agonists. While this should cause $\mathrm{CBD}$ to reduce the effects of THC, it may potentiate THC's effects by increasing $\mathrm{CB}_{1}$ receptor density or through another $\mathrm{CB}_{1}$-related mechanism [27]. It is also an inverse agonist of $\mathrm{CB}_{2}$ receptors. $\mathrm{CBD}$ can counteract some of the functional consequences of $\mathrm{CB}_{1}$ activation in the brain, possibly by indirect enhancement of adenosine $A_{1}$ receptors activity through Equilibrative Nucleoside Transporter (ENT) inhibition.

CBD helps to augment some of THC's beneficial effects, as it reduces the psychoactivity of THC to enhance its tolerability and widen its therapeutic window [94]. This may partly explain why users of cannabis preparations with high CBD: THC ratios are less likely to develop psychotic symptoms than those who consume preparations with low CBD: THC ratios [95]. The botanical drug nabiximols, which contains equal amounts of THC and CBD, relieves spasticity and pain in multiple sclerosis more effectively than THC alone, possibly because CBD's effects allow patients to tolerate higher amounts of THC [27].

CBD exerts its antiepileptic effects through several different mechanisms. The most beneficial route has not fully been determined yet due to lack of sufficient evidence. It is a "multitarget" compound. At low micromolar to sub-micromolar concentrations, CBD is a blocker of ENT, the orphan G-protein-coupled receptor GPR55, and the Transient Receptor Potential of Melastatin Type 8 (TRPM8) channel. Conversely, CBD enhances the activity of the 5-HT1a receptor, the a3 and a1 glycine receptors, the Transient Receptor Potential of Ankyrin type 1 (TRPA1) channel, and has a bidirectional effect on intracellular calcium [19,96]. At higher micromolar concentrations, CBD activates the nuclear peroxisome proliferator-activated receptor $\gamma$ and the Transient Receptor Potential of Vanilloid type 1 (TRPV1) and 2 (TRPV2) channels while also inhibiting cellular uptake and fatty acid amide hydrolase-catalyzed degradation of AE [19,93]. Finally, CBD's polyphenolic nature makes it a potent antioxidant. CBD may also supplement the antispastic effects of THC (e.g., via local potentiation of glycine mediated signaling, inhibition of endocannabinoid degradation, or retardation of demyelination through anti-inflammatory, antioxidant, and anti-excitotoxic mechanisms). $\mathrm{CBD}$ has proven beneficial in experimental models of several neurologic disorders, including those of seizure and epilepsy [97], as have other cannabinoids such as Cannabichromene (CBC) and the propyl homologs of THC and CBD (respectively, D9-Tetrahydrocannabivarin [THCV] and Cannabidivarin [CBDV]). THCV exhibits high affinity for cannabinoid receptors and acts as a neutral $\mathrm{CB}_{1}$ antagonist and partial $\mathrm{CB}_{2}$ agonist with efficacy in an animal model of Parkinson's disease [98]. CBC influences adult neural stem cell differentiation by reducing generation of new astrocytes potentially involved in neuro-inflammation $[99,100]$. 
Citation: Babayeva M, Fuzailov M, Rozenfeld P, Basu P (2014) Marijuana Compounds: A Non-Conventional Therapeutic Approach to Epilepsy in Children. J Addict Addictv Disord 1: 002.

CBDV and, to a far smaller extent, THCV produce anticonvulsant effects in animal models of epilepsy, likely via non- $\mathrm{CB}_{1} / \mathrm{CB}_{2}$ mechanisms. Like CBD, these compounds interact with TRPV1, TRPV2, TRPA1, and TRPM8 channels, but their molecular pharmacology and mechanisms of action are less well understood.

\begin{tabular}{|l|l|}
\hline \multicolumn{1}{|c|}{ Cannabinoid } & \multicolumn{1}{c|}{ Molecular target(s) } \\
\hline D9-Tetrahydrocannabinol (D9-THC) & $\mathrm{CB}_{1} \mathrm{R}, \mathrm{CB}_{2} \mathrm{R}, \mathrm{TRPV} 1, \mathrm{TRPV} 2$ \\
\hline D9-Tetrahydrocannabivarin (D9-THCV) & $\mathrm{CB}_{1}, \mathrm{CB}_{2}, \mathrm{TRPV} 1, \mathrm{TRPV} 3, \mathrm{TRPV} 4$ \\
\hline Cannabidiol (CBD) & $\begin{array}{l}\text { ENT, GPR55, TRPV1, TRPV2, TRPV3, } \\
\text { TRPA1, FAAH, TRPM8, adenosine, 5HT1 }\end{array}$ \\
\hline Cannabidivarin (CBDV) & TRPV4, DAGL $\alpha$ \\
\hline Cannabinol (CBN) & $\mathrm{CB}_{1}$ R, TRPV4, TRPA1 \\
\hline
\end{tabular}

Table 1: Proposed molecular targets for plant cannabinoids investigated in animal models of seizure.

\section{Effects of Cannabinoid Compounds on Epilepsy and Seizure}

Some of illicit drugs can affect seizure and epilepsy progress. Recent studies assessed the prevalence of illicit drug use among epilepsy patients and its effects on the disease. In these studies, it was reported that frequent use of cocaine, amphetamines or heroin increases seizure risk [101]. Another study stated that heroin use is a risk factor and marijuana use a protective factor for new-onset seizures [102].

Preclinical studies, mainly in the 1970s, studied the effects of cannabis on animal models of seizure and epilepsy. The results of these studies, which are summarized in (Table 1), demonstrated mixed efficacy in acute seizure models in various species [103-110].

Reproduced with permission from Devinsky et al., [27], Cannabidiol: Pharmacology and potential therapeutic role in epilepsy and other neuropsychiatric disorders (Table 1,2) Epilepsia.

\section{Potential Therapy of Epilepsy Using Marijuana}

Unfortunately, a substantial proportion of children diagnosed with epilepsy doesn't respond well to treatment, and for these patients, the clinical goal is to find an optimal treatment [111]. Marijuana ingredients have created a significant research interest as potential therapy options in epilepsy treatment.

CBD bears investigation in neuropsychiatric disorders such as epilepsy, anxiety, schizophrenia, addiction, and neonatal hypoxic-ischemicencephalopathy [27]. $\mathrm{CBD}$ has shown to be protective against epilepsy, anxiety, and psychosis and to ameliorate diseases of the basal ganglia, such as Parkinsonism and Huntington's disease $[8,9]$.

CBD has proven beneficial in experimental models of several neurologic disorders, including those of seizure and epilepsy [7,107]. Significant anticonvulsant effects of $\mathrm{CBD}\left(\mathrm{ED}_{50}=120 \mathrm{mg} / \mathrm{kg}\right)$ were found in mice [112]. More recently, CBD has been shown to have anticonvulsant effect in vitro and in vivo models. CBD caused concentration-related and region-dependent attenuation of chemically induced epileptiform activity in hippocampal brain slices [113]. Furthermore, in vivo studies reported the effects of pure CBD in established rodent seizure models, the acute pilocarpine model of temporal lobe seizure and the penicillin model of partial seizure [114]. In the pilocarpine model CBD significantly reduced the percentage of animals experiencing the most severe seizures. In the penicillin model, CBD significantly decreased the percentage mortality as a result of seizures; $\mathrm{CBD}$ also decreased the percentage of animals experiencing the most severe tonic-clonic seizures. Moreover, CBD reduced seizure severity and mortality in an in vivo model of generalized seizures $[113,114]$. These results extend the anti-convulsant profile of CBD; when combined with a reported absence of psychoactive effects, this evidence strongly supports CBD as a

\begin{tabular}{|c|c|c|}
\hline Plant cannabinoid & Model & Efficacy \\
\hline \multirow{2}{*}{ D9-Tetrahydrocannabinol (D9-THC) } & Generalized seizure (e.g., MES, PTZ, $6 \mathrm{~Hz}, 60 \mathrm{~Hz}$, nicotine, and strychnine) & Y \\
\hline & Temporal lobe epilepsy & Y \\
\hline \multirow{4}{*}{ Synthetic CB1R agonists (e.g., WIN55-212) } & Generalized seizure (MES, PTZ, amygdala kindling) & Y \\
\hline & Partial seizure with secondary generalization (penicillin and maximal dentate gyrus activation) & Y \\
\hline & Temporal lobe epilepsy & Y \\
\hline & Absence epilepsy (WAG/Rij) & Mixed effect \\
\hline \multirow{4}{*}{ Synthetic CB1R antagonists (e.g., SR141716A) } & Generalized seizure (MES and PTZ) & $\mathrm{Na}$ \\
\hline & Absence epilepsy (WAG/Rij) & $\mathrm{N}$ \\
\hline & Partial seizures with secondary generalization (penicillin but not maximal dentate gyrus activation) & $\mathrm{Na}$ \\
\hline & Epileptogenesis (juvenile head trauma but not kainic acid) & Y \\
\hline D9-Tetrahydrocannabivarin (D9-THCV) & Generalized seizure & Y \\
\hline \multirow{3}{*}{ Cannabidiol (CBD) } & $\begin{array}{l}\text { Generalized seizure (MES, PTZ, } 6 \mathrm{~Hz}, 60 \mathrm{~Hz} \text {, picrotoxin, isonicotinic acid, bicuculline, hydrazine, limbic } \\
\text { kindling (electrical), and strychnine but not 3-mercaptoproprionic acid) }\end{array}$ & Y \\
\hline & Temporal lobe convulsions/status epilepticus & Y \\
\hline & Partial seizures with secondary generalization (penicillin but not cobalt) & Y \\
\hline \multirow{3}{*}{ Cannabidivarin (CBDV) } & Generalized seizure (MES, PTZ, and audiogenic) & Y \\
\hline & Temporal lobe convulsions/status epilepticus & Y \\
\hline & Partial seizures with secondary generalization (penicillin only) & Y \\
\hline Cannabinol (CBN) & Generalized seizure (MES only) & Y \\
\hline
\end{tabular}

Table 2: Cannabinoid efficacy in animal models of seizure and epilepsy. 
therapeutic candidate for a diverse range of human epilepsies. The antiepileptic mechanisms of CBD are not well investigated. Some authors reported a role for the cannabinoid $\mathrm{CB}_{1}$ receptor in modulating seizure activity $[115,116]$. Devinsky indicated that cannabinoids produce anticonvulsant effects via non- $\mathrm{CB}_{1} / \mathrm{CB}_{2}$ mechanisms (Devinsky O et al., 2014) [27].

Clinical studies (phase I clinical trial) also suggested that CBD has an anticonvulsant potential [117]. In addition, CBD is very well tolerated and doesn't produce the psychotic symptoms even at high doses [118]. Pure CBD appears to be an ideal candidate among phytocannabinoids as a therapy for treatment-resistant epilepsy. A first step in this direction is to systematically investigate the safety, pharmacokinetics, and obtain an initial signal regarding efficacy at different dosages [119].

THC, the other (psychoactive) ingredient of marijuana plant, also aids in reducing epileptic seizures [21]. Results from earlier clinical studies were reported on the therapeutic application of delta 9-THC (Dronabinol, Marinol) in 8 children. These studies indicated that THC reduced spasticity, improved dystonia, increased initiative (with low dose), increased interest in the surroundings, and anticonvulsive action [120]. THC had different effects in reducing seizure frequency and severity and reports of THC outcomes were not consistent among all studies. Several studies reported that THC showed no potential benefit in treating seizures while other studies showed potentiation of convulsive effects, and that THC actually provoked epileptiform activity [121]. Additional studies [122] reported that THC administration led to dose-limiting toxicities and tolerance to anti-seizure effects. Effect of THC, with THC derivatives or synthetic agonists (which activate $\mathrm{CB}_{1}$ receptors), varied in yielding therapeutic benefit for patients with epilepsy [27].

Cases of epilepsy that have not responded to traditional therapeutic intervention in pediatric patients have led parents to explore the use of cannabis enriched products. A recent US survey conducted with 19 parents, 12 of which had children diagnosed with Dravet syndrome, revealed that parents admitted to using CBD-enriched cannabis in their children, to control resistant seizures. An average twelve AEDs were tried unsuccessfully before parents initiated CBD treatment. The reported doses of cannabidiol ranged from less than $0.5 \mathrm{mg} / \mathrm{kg} /$ day to $28.6 \mathrm{mg} / \mathrm{kg} /$ day. Seizure frequency before administering cannabidiol ranged from 2 seizures per week to 250 per day. The duration of treatment lapsed from two weeks to over one year. The results of this study indicated that $84 \%$ of parents noted a reduction in the frequency of seizures, while two parents (11\%) reported that their child became seizure-free after more than 4 months of cannabidiol use. Eight parents (42\% ) reported a greater than $80 \%$ reduction in seizure frequency, three (16\%) reported a greater than $50 \%$ decrease in seizure frequency, three parents $(16 \%)$ indicated a decline in seizure frequency of greater than $25 \%$ reduction and three parents reported no changes in frequency [123].

Similar to traditional treatment regimens, cannabis- based drugs enriched in cannabidiol [124] presented findings in support of treatment, as well adverse effects in children. Parents highlighted some of the beneficial outcomes of the CBD drugs their children experienced such as better sleep patterns, increased alertness and an overall positive change in mood while being treated with CBD-enriched cannabis. AEDs do not have as many positive side effects and on the contrary place children at risk for severe side effects such as irritability, insomnia, and aggressive behavior. Due to the notable efficacy of CBD-enriched medications, parents were able to slowly taper their child off of other AEDs and led to an improved quality of life [123].

A report about an adjunctive treatment of a child with Dravet syndrome with a mixture of $\mathrm{CBD}$ and THC was broadcast recently by a news corporation, which received widespread attention. The adjunctive therapy was started with a high concentration CBD: THC. This extract reduced the seizure frequency from nearly 50 convulsive seizures per day to now 2-3 nocturnal convulsions per month. This effect has persisted for the last 20 months, and the child has been successfully weaned from her other AEDs [125].

Recently, a review was conducted to assess the efficacy of marijuana, or marijuana's constituents in the treatment of people with epilepsy. Four studies were reviewed as part of this analysis. None of the four studies provided sufficient information to address the primary outcome of this review; seizure freedom for 12 months or three times the longest inter-seizure interval. Of the secondary outcomes of analysis, the only one that could be supported was that there were no significant side effects in any of the patients studied, except one study, which reported mild drowsiness. The authors concluded that no reliable decisions can be drawn regarding the efficacy of cannabinoids as a treatment for epilepsy [126].

A new international, multi-center study led by researchers from UCSF Benioff Children's Hospital is the first to evaluate whether purified cannabinoid is effective in treating severe forms of childhood epilepsy. The trial will enroll a total of 150 patients. The patients are all between the ages of one and 18 with intractable epilepsies shown to be resistant to many if not all of the antiepileptic treatments, including drugs and a ketogenic diet. For one year the patients will be carefully monitored [127].

Even though marijuana and cannabinoids can produce the therapeutic effects they also may create dangerous health problems. Chronic marijuana use has been related to various cognitive problems such as addiction, distorted perceptions, impaired coordination, difficulty in thinking and problem solving, ongoing problems with learning and memory [128]. Long-term use can increase the risk of damaging the lungs and reproductive system. It has also been linked to heart attacks [129]. There is a possibility for the children with epilepsy to be affected by other illnesses in adulthood after medical marijuana use in childhood. There are potential risks for epileptic children to be treated with cannabinoids.

\section{Conclusion}

Chief concerns regarding the use of medical marijuana in children and adults include lack of standardization and regulation, imprecise dosing, possible adverse side effects and medication interactions. This would result in products being manufactured or grown, which pose questionable threats on quality and composition. The levels of THC and CBD are crucial due to their different mechanisms and psychotropic activity Although many marijuana strains used for epilepsy treatment are reported to have high CBD: THC ratios, THC is more potent than $\mathrm{CBD}$, so low doses of THC can have adverse effects, especially in young children. In addition to THC and CBD, there are over 80 other cannabinoids and 300 non-cannabinoid chemicals naturally found in the cannabis plant [119]. These extracts could also contain contaminants, such as fungus and pesticides, which may cause long-term organ damage. 
Citation: Babayeva M, Fuzailov M, Rozenfeld P, Basu P (2014) Marijuana Compounds: A Non-Conventional Therapeutic Approach to Epilepsy in Children. J Addict Addictv Disord 1: 002.

Research studies have provided strong evidence for safety and anticonvulsant properties of medical marijuana. However, the lack of pure, pharmacologically active compounds and legal restrictions have prevented broad clinical research. Further studies are needed to confine data on safety, pharmacokinetics and interactions of cannabinoids with other AEDs.

\section{References}

1. Bostwick JM (2012) Blurred boundaries: the therapeutics and politics of medical marijuana. Mayo Clin Proc 87: 172-186.

2. Roffman R (2014) Marijuana Nation. Pegasus Books, New York, NY.

3. Marijuana Resource Center. ONDCP.

4. 14th International Congress on Schizophrenia Research (ICOSR) (2013) Cannabis Use in Teens Linked to Irreparable Drop in IQ, Medspace Multispeciality.

5. Drug Facts: Marijuana (2014) NIDA.

6. Fusar-Poli P, Crippa JA, Bhattacharyya S, Borgwardt SJ, Allen P, et al (2009) Distinct effects of \{delta\}9-tetrahydrocannabinol and cannabidiol on neural activation during emotional processing. Arch Gen Psychiatry 66: 95105.

7. Hill AJ, Williams CM, Whalley BJ, Stephens GJ (2012) Phytocannabinoids as novel therapeutic agents in CNS disorders. Pharmacol Ther 133: 79-97.

8. luvone T, Esposito G, De Filippis D, Scuderi C, Steardo L (2009) Cannabidiol: a promising drug for neurodegenerative disorders? CNS Neurosci Ther 15: $65-75$

9. Scuderi C, Filippis DD, luvone T, Blasio A, Steardo A, et al. (2009) Cannabidiol in medicine: a review of its therapeutic potential in CNS disorders. Phytother Res 23: 597-602.

10. What Are the Differences between Cannabis Indica and Cannabis Sativa, and How Do They Vary in Their Potential Medical Utility? (2011) Golden State Collective (GSC) Cannabis Laboratories. "Cannabis Sativa and Indica Compared".

11. Mechoulam R (2005) Plant cannabinoids: a neglected pharmacological treasure trove. Br J Pharmacol 146: 913-915.

12. Shen M, Thayer SA (1999) Delta9-tetrahydrocannabinol acts as a partia agonist to modulate glutamatergic synaptic transmission between rat hippocampal neurons in culture. Mol Pharmacol 55: 8-13.

13. Murase R, Kawamura R, Singer E, Pakdel A, Sarma P, et al. (2014) Targeting multiple cannabinoid antitumor pathways with a resorcinol derivative leads to inhibition of advanced stages of breast cancer. $\mathrm{Br} \mathrm{J}$ Pharmacol 171 4464-4477.

14. Joy J, Watson S, Benson J (1999) Marijuana and medicine: Assessing the science base. National Academies Press. Washington, D.C.

15. Mechoulam R, Shvo Y (1963) Hashish. I. The structure of cannabidiol. Tetrahedron 19: 2073-2078.

16. Hillig KW, Mahlberg PG (2004) A chemotaxonomic analysis of cannabinoid variation in Cannabis (Cannabaceae). Am J Bot 91: 966-975

17. Drug Facts: Is Marijuana Medicine? (2014) NIDA.

18. Hiley CR (2009) Endocannabinoids and the heart. J Cardiovasc Pharmacol 53: $267-276$.

19. Pertwee RG (2008) The diverse $C B_{1}$ and $C B_{2}$ receptor pharmacology of three plant cannabinoids: delta9-tetrahydrocannabinol, cannabidiol and delta9-tetrahydrocannabivarin. Br J Pharmacol 153: 199-215.

20. Xu JY, Chen C (2014) Endocannabinoids in Synaptic Plasticity and Neuroprotection. Neuroscientist

21. Hegde V, Nagarkatti M, Nagarkatti P (2010) Cannabinoid receptor activation leads to massive mobilization of myeloid-derived suppressor cells with potent immunosuppressive properties. Eur J Immunol 40: 3358-3371.
22. Piomelli D (2003) The molecular logic of endocannabinoid signalling. Nat Rev Neurosci 4: 873-884

23. Matsuda LA, Lolait SJ, Brownstein MJ, Young AC, Bonner TI (1990) Structure of a cannabinoid receptor and functional expression of the cloned cDNA. Nature 346: 561-564

24. Herkenham M, Lynn AB, Johnson MR, Melvin LS, de Costa BR, et al. (1991) Characterization and localization of cannabinoid receptors in rat brain: a quantitative in vitro autoradiographic study. J Neurosci 11: 563-583.

25. Galiegue S, Mary S, Marchand J, Dussossoy D, Carrière D, et al. (1995) Expression of central and peripheral cannabinoid receptors in human immune tissues and leukocyte subpopulations. Eur J Biochem 232: 54-61.

26. Pacher $P$, Mechoulam $R$ (2011) Is lipid signaling through cannabinoid 2 receptors part of a protective system? Prog Lipid Res 50: 193-211.

27. Devinsky O, Cilio MR, Cross H, Fernandez-Ruiz J, French J, et al. (2014) Cannabidiol: pharmacology and potential therapeutic role in epilepsy and other neuropsychiatric disorders. Epilepsia 55: 791-802.

28. Robert J Meyer (2004) Potential Merits of Cannabinoids for Medical Uses. FDA.

29. Haney M (2002) Effects of smoked marijuana in healthy and HIV + marijuana smokers. J Clin Pharmacol 42: 34-40.

30. Molina P, Amedee A, LeCapitaine N, Zabaleta J, Mohan M, et al. (2014) Modulation of Gut-Specific Mechanisms by Chronic $\delta(9)$-Tetrahydrocannabinol Administration in Male Rhesus Macaques Infected with Simian Immunodeficiency Virus: A Systems Biology Analysis. AIDS Res Hum Retrov 30: 567-578.

31. deVries M, van Rijckevorsel DC, Wilder-Smith OH, van Goor H (2014) Dronabinol and chronic pain: importance of mechanistic considerations. Expert Opin Pharmacother 15: 1525-1534.

32. Benyamina A, Reynaud M (2014) [Therapeutic use of cannabis derivatives]. Rev Prat 64: 165-168.

33. Reynolds TD, Osborn HL (2013) The use of cannabinoids in chronic pain. BMJ Case Rep 2013

34. Haney M, Cooper ZD, Bedi G, Vosburg SK, Comer SD, et al. (2013) Nabilone decreases marijuana withdrawal and a laboratory measure of marijuana relapse. Neuropsychopharmacology 38: 1557-1565.

35. Levin FR, Mariani JJ, Brooks DJ, Pavlicova M, Cheng W, et al. (2011) Dronabinol for the treatment of cannabis dependence: a randomized, double-blind, placebo-controlled trial. Drug Alcohol Depend 116: 142-150.

36. GM Pharmaceutical (2003) Cannabis-based medicines--GW pharmaceuticals: high CBD, high THC, medicinal cannabis--GW pharmaceuticals, THC: CBD. Drugs RD 4: 306-309.

37. Syed YY, McKeage K, Scott LJ (2014) Delta-9-tetrahydrocannabinol/cannabidiol (sativex(®)): a review of its use in patients with moderate to severe spasticity due to multiple sclerosis. Drugs 74: 563-578.

38. Gardner F (2013) Epidiolex. GW Pharmaceutical.

39. Sativex-Investigational Cannabis-Based treatment for Pain and Multiple Sclerosis. Drug Development Technology.

40. Budney AJ, Roffman R, Stephens RS, Walker D (2007) Marijuana dependence and its treatment. Addict Sci ClinPract 4: 4-16.

41. Lucas P, Reiman A, Earleywine M, McGowan S, Oleson M, et al. (2013) Cannabis as a substitute for alcohol and other drugs: A dispensary-based survey of substitution effect in Canadian medical cannabis patients. Addiction Research \& Theory 21: 435-442.

42. Crean RD, Crane NA, Mason BJ (2011) An evidence based review of acute and long-term effects of cannabis use on executive cognitive functions. $J$ Addict Med 5: 1-8.

43. Sewell RA, Ranganathan M, D'Souza DC (2009) Cannabinoids and psychosis. Int Rev Psychiatry 21: 152-162. 
Citation: Babayeva M, Fuzailov M, Rozenfeld P, Basu P (2014) Marijuana Compounds: A Non-Conventional Therapeutic Approach to Epilepsy in Children. J Addict Addictv Disord 1: 002.

44. Johns A (2001) Psychiatric effects of cannabis. Br J Psychiatry 178: 116-122.

45. Bromfield EB, Cavazos JE, Sirven JI (2006). An Introduction to Epilepsy Chapter 2, Clinical Epilepsy. American Epilepsy Society. West Hartford CT.

46. Seizures and Epilepsy in Children. John Hopkins Medicine, Health Library.

47. Epilepsy Stats and Facts. Epilepsy Foundation.

48. Epilepsy Fast Facts (2013) CDC

49. Response to Therapy. Epilepsy Foundation, Greater Chicago.

50. Epilepsy (2013) Kids Health.

51. DiPiro J, Talbert R, Yee G, Matzke G, Wells B, et al. (2011) Pharmacotherapy: A Pathophysiologic Approach. ( $8^{\text {th }}$ edn). McGraw-Hill Medical, New York, USA.

52. Wilfong A (2014) Epilepsy syndromes in children.

53. Epilepsy (2013) University of Maryland Medical Center.

54. (2006) Basic Mechanisms Underlying Seizures and Epilepsy. In: Bromfield EB, Cavazos JE, Sirven JI (eds.). An Introduction to Epilepsy. American Epilepsy Society. West Hartford (CT), USA.

55. Liu YM, Wang HS (2013) Medium-chain triglyceride ketogenic diet, an effective treatment for drug-resistant epilepsy and a comparison with other ketogenic diets. Biomed J 36: 9-15.

56. Mantoan L, Walker M (2011) Treatment options in juvenile myoclonic epilepsy. Curr Treat Options Neurol 13: 355-370.

57. Ibrahim GM, Rutka JT, Snead OC (2014) Epilepsy surgery in childhood: no longer the treatment of last resort. CMAJ 186: 973-974 .

58. Schmidt D (2009) Drug treatment of epilepsy: options and limitations. Epilepsy Behav 15: 56-65.

59. Hamiwka L, Grondin R (2009-2010) Epilepsy Surgery: Targeting Seizures with Cortical Mapping. J Pediatric directions 35: 12-17.

60. Wheless JW (2009) Managing severe epilepsy syndromes of early childhood. J Child Neurol 24: 24-32.

61. Ceulemans B, Boel M, Leyssens K, Van Rossem C, Neels P, et al. (2012) Successful use of fenfluramine as an add-on treatment for Dravet syndrome. Epilepsia 53: 1131-1139.

62. Kwong AK, Fung CW, Chan SY, Wong VC (2012) Identification of SCN1A and PCDH19 mutations in Chinese children with Dravet syndrome. PLoS One 7: 41802

63. Xu XJ, Zhang YH, Sun HH, Liu XY, Wu HS, et al. (2012) [Phenotype and SCN1A gene mutation screening in 39 families with generalized epilepsy with febrile seizures plus]. Zhonghua ErKeZaZhi 50: 580-586.

64. Barba C, Parrini E, Coras R, Galuppi A, Craiu D, et al. (2014) Co-occurring malformations of cortical development and SCN1A gene mutations. Epilepsia 55: 1009-1019.

65. Riva D, Vago C, Pantaleoni C, Bulgheroni S, Mantegazza M, et al. (2009) Progressive neurocognitive decline in two children with Dravet syndrome, de novo SCN1A truncations and different epileptic phenotypes. Am J Med Genet A 149: 2339-2345.

66. Hirose S, Scheffer IE, Marini C, De Jonghe P, Andermann E, et al. (2013) SCN1A testing for epilepsy: application in clinical practice. Epilepsia 54: 946952.

67. Auvin S (2014) Should we still consider Dravet syndrome an epileptic encephalopathy? Epilepsy Behav 36: 80-81.

68. Chiron C, Dulac O (2011) The pharmacologic treatment of Dravet syndrome. Epilepsia 52: 72-75.

69. Kneen R, Appleton RE (2006) Alternative approaches to conventional antiepileptic drugs in the management of paediatric epilepsy. Arch Dis Child 91: 936-941.
70. Catarino C, Liu J, loannisLiagkouras I, Gibbons V, Labrum R, et al. (2011) Dravet syndrome as epileptic encephalopathy: evidence from long-term course and neuropathology. Brain 134: 2982-3010.

71. Chiron C (2011) Current therapeutic procedures in Dravet syndrome. Dev Med Child Neurol 53: 16-18.

72. Brodie MJ, Sills GJ (2011) Combining antiepileptic drugs--rational polytherapy? Seizure 20: 369-375.

73. Guerrini R, Aicardi J (2003) Epileptic encephalopathies with myoclonic seizures in infants and children (severe myoclonic epilepsy and myoclonic-astatic epilepsy). J Clin Neurophysiol 20: 449-461.

74. VanStraten AF, Ng YT (2012) Update on the management of Lennox-Gastaut syndrome. Pediatr Neurol 47: 153-161.

75. Widdess-Walsh P, Dlugos D, Fahlstrom R, Joshi S, Shellhaas R, et al. (2013) Lennox-Gastaut syndrome of unknown cause: phenotypic characteristics of patients in the Epilepsy Phenome/Genome Project. Epilepsia 54: 1898-1904.

76. Markand ON (2003) Lennox-Gastaut syndrome (childhood epileptic encephalopathy). J Clin Neurophysiol 20: 426-441.

77. Crumrine PK (2011) Management of seizures in Lennox-Gastaut syndrome. Paediatr Drugs 13: 107-118.

78. Lund C, Brodtkorb E, Oye AM, Røsby O, Selmer KK (2014) CHD2 mutations in Lennox-Gastaut syndrome. Epilepsy Behav 33: 18-21.

79. Selmer KK, Lund C, Brandal K, Undlien DE, Brodtkorb E (2009) SCN1A mutation screening in adult patients with Lennox-Gastaut syndrome features. Epilepsy Behav 16: 555-557.

80. Archer JS, Warren AE, Stagnitti MR, Masterton RA, Abbott DF, et al. (2014) Lennox-Gastaut syndrome and phenotype: Secondary network epilepsies. Epilepsia 55: 1245-1254.

81. Ren LK, Wu LW, Jin LR, Gao W, Shao XQ (2003) [Characteristics of clinical manifestations and EEG of Lennox-Gastaut syndrome]. Zhonghua Er Ke Za Zhi 41: 7-10

82. Doose H (1992) Myoclonic-astatic epilepsy. Epilepsy Res Suppl 6: 163-168.

83. Tang S, Pal DK (2012) Dissecting the genetic basis of myoclonic-astatic epilepsy. Epilepsia 53: 1303-1313.

84. Oguni H, Tanaka T, Hayashi K, Funatsuka M, Sakauchi M, et al. (2002) Treatment and long-term prognosis of myoclonic-astatic epilepsy of early childhood. Neuropediatrics 33: 122-132.

85. Stephani U (2006) The natural history of myoclonic astatic epilepsy (Doose syndrome) and Lennox-Gastaut syndrome. Epilepsia 47: 53-55.

86. Inoue T, Ihara $\mathrm{Y}$, Tomonoh $\mathrm{Y}$, Nakamura N, Ninomiya S, et al. (2014) Early onset and focal spike discharges as indicators of poor prognosis for myocIonic-astatic epilepsy. Brain Dev 36: 613-619.

87. Asadi-Pooya AA, Sharifzade M (2013) West syndrome in South Iran: electro-clinical manifestations. Iran J Child Neurol 7: 40-44.

88. Fridley J, Reddy G, Curry D, Agadi S (2013) Surgical treatment of pediatric epileptic encephalopathies. Epilepsy Res Treat 2013: 720841.

89. Cvitanovic-Sojat L, Gjergja R, Sabol Z, Hajnzic TF, Sojat T (2005) [Treatment of West syndrome]. Acta Med Croatica 59: 19-29.

90. De Petrocellis L, Cascio MG, DiMarzo V (2004) The endocannabinoid system: a general view and latest additions. Br J Pharmacol 141: 765-774.

91. Basavarajappa BS (2007) Neuropharmacology of the endocannabinoid signaling system-molecular mechanisms, biological actions and synaptic plasticity. Curr Neuropharmacol 5: 81-97.

92. Di Marzo V, Fontana A (1995) Anandamide, an endogenous cannabinomimetic eicosanoid: 'killing two birds with one stone'. Prostaglandins Leukot Essent Fatty Acids 53: 1-11. 
Citation: Babayeva M, Fuzailov M, Rozenfeld P, Basu P (2014) Marijuana Compounds: A Non-Conventional Therapeutic Approach to Epilepsy in Children. J Addict Addictv Disord 1: 002.

93. Leweke FM, Piomelli D, Pahlisch F, Muhl D, Gerth CW, et al. (2012) Cannabidiol enhances anandamide signaling and alleviates psychotic symptoms of schizophrenia. Transl Psychiatry 2: 94.

94. Karniol IG, Carlini EA (1973) Pharmacological interaction between cannabidiol and delta 9-tetrahydrocannabinol. Psychopharmacologia 33: 53-70.

95. Schubart CD, Sommer IE, van Gastel WA, Goetgebuer RL, Kahn RS, et al. (2011) Cannabis with high cannabidiol content is associated with fewer psychotic experiences. Schizophr Res 130: 216-221.

96. Ryan D, Drysdale AJ, Lafourcade C, Pertwee RG, Platt B (2009) Cannabidiol targets mitochondria to regulate intracellular $\mathrm{Ca}^{2+}$ levels. J Neurosci 29 2053-2063.

97. Hill A, Hill T, Whalley B (2013) The Development of Cannabinoid Based Therapies for Epilepsy. In: Eric Murillo-Rodríguez, Emmanuel S Onaivi, Nissar A Darmani, Edward Wagner (eds.). Endocannabinoids: Molecular, Pharmacological, Behavioral and Clinical Features. Bentham Science, Oak Park, IL, USA.

98. Garcia C, Palomo-Garo C, García-Arencibia M, Ramos J, Pertwee R, et al (2011) Symptom-relieving and neuroprotective effects of the phytocannabinoid $\Delta^{9}$-THCV in animal models of Parkinson's disease. Br J Pharmacol 163 1495-1506.

99. Shinjyo N, Di Marzo V (2013) The effect of cannabichromene on adult neural stem/progenitor cells. Neurochem Int 63: 432-437.

100.Di Marzo V, Bifulco M, De Petrocellis L (2004) The endocannabinoid system and its therapeutic exploitation. Nat Rev Drug Discov 3: 771-784.

101. Hamerle M, Ghaeni L, Kowski A, Weissinger F, Holtkamp M (2014) Cannabis and other illicit drug use in epilepsy patients. Eur J Neurol 21: 167-170.

102. Ng SK, Brust JC, Hauser WA, Susser M (1990) Illicit drug use and the risk of new-onset seizures. Am J Epidemiol 132: 47-57.

103. Ghosh P, Bhattacharya SK (1978) Anticonvulsant action of cannabis in the rat: role of brain monoamines. Psychopharmacology (Berl) 59: 293-297.

104. Labrecque G, Hallé S, Berthiaume A, Morin G, Morin PJ (1978) Potentiation of the epileptogenic effect of penicillin $\mathrm{G}$ by marihuana smoking. Can $\mathrm{J}$ Physiol Pharmacol 56: 87-96.

105.Segal M, Edelstein EL, Lerer B (1978) Interaction between delta-6-Tetrahydrocannabinol (delta-6-THC) and lithium at the blood brain barrier in rats. Experientia 34: 629.

106. Stadnicki SW, Schaeppi U, Rosenkrantz H, Braude MC (1974) Delta9-tetrahydrocannabinol: subcortical spike bursts and motor manifestations in a Fischer rat treated orally for 109 days. Life Sci 14: 463-472.

107. Martin P, Consroe P (1976) Cannabinoid induced behavioral convulsions in rabbits. Science 194: 965-967.

108. Consroe P, Benedito M, Leite J, Carlini EA, Mechoulam R (1982) Effects of cannabidiol on behavioral seizures caused by convulsant drugs or current in mice. Eur J Pharmacol 83:293-298.

109. Izquierdo I, Tannhauser M (1973) Letter: The effect of cannabidiol on maximal electroshock seizures in rats. J Pharm Pharmacol 25: 916-917.

110. Chesher GB, Jackson DM (1974) Anticonvulsant effects of cannabinoids in mice: drug interactions within cannabinoids and cannabinoid interactions with phenytoin. Psychopharmacologia 37: 255-264.
111. Connock M, Frew E, Evans BW, Bryan S, Cummins C, et al. (2006) The clinical effectiveness and cost-effectiveness of newer drugs for children with epilepsy. A systematic review. Health Technol Assess 10: iii, ix-118.

112. Karler R, Cely W, Turkanis SA (1974) Anticonvulsant properties of delta 9-tetrahydrocannabinol and other cannabinoids. Life Sci 15: 931-947.

113. Jones NA, Hill AJ, Smith I, Bevan SA, Williams CM, et al. (2010) Cannabidiol displays antiepileptiform and antiseizure properties in vitro and in vivo. $J$ Pharmacol Exp Ther 332: 569-577.

114.Jones NA, Glyn SE, Akiyama S, Hill TD, Hill AJ, et al. (2012) Cannabidiol exerts anti-convulsant effects in animal models of temporal lobe and partial seizures. Seizure 21: 344-352.

115. Wallace MJ, Wiley JL, Martin BR, DeLorenzo RJ (2001) Assessment of the role of CB1 receptors in cannabinoid anticonvulsant effects. Eur J Pharmacol 428: 51-57.

116.Wallace MJ, Martin BR, DeLorenzo RJ (2002) Evidence for a physiological role of endocannabinoids in the modulation of seizure threshold and severity. Eur J Pharmacol 452: 295-301.

117. Cunha JM, Carlini EA, Pereira AE, Ramos OL, Pimentel C, et al. (1980) Chronic administration of cannabidiol to healthy volunteers and epileptic patients. Pharmacology 21: 175-185.

118. Bhattacharyya S, Fusar-Poli P, Borgwardt S, Martin-Santos R, Nosarti C, et al. (2009) Modulation of mediotemporal and ventrostriatal function in humans by Delta9-tetrahydrocannabinol: a neural basis for the effects of Cannabis sativa on learning and psychosis. Arch Gen Psychiatry 66: 442-451.

119. Cilio MR, Thiele EA, Devinsky O (2014) The case for assessing cannabidiol in epilepsy. Epilepsia 55: 787-790.

120.Lorenz R (2004) On the application of cannabis in paediatrics and epileptology. Neuro Endocrinol Lett 25: 40-44.

121. Treatment Options. Epilepsy Foundation, Colorado.

122. Karler R, Calder LD, Turkanis SA (1986) Prolonged CNS hyperexcitability in mice after a single exposure to delta-9-tetrahydrocannabinol. Neuropharmacology 25: 441-446.

123.Porter BE, Jacobson C (2013) Report of a parent survey of cannabidiol-enriched cannabis use in pediatric treatment-resistant epilepsy. Epilepsy Behav 29: 574-577.

124. Englund A, Morrison PD, Nottage J, Hague D, Kane F, et al. (2013) Cannabidiol inhibits THC-elicited paranoid symptoms and hippocampal-dependent memory impairment. J Psychopharmacol 27: 19-27.

125. Maa E, Figi P (2014) The case for medical marijuana in epilepsy. Epilepsia 55: $783-786$

126. Gloss D, Vickrey B (2012) Cannabinoids for epilepsy. Cochrane Database Syst Rev 6: CD009270.

127. Marijuana-Derived Epilepsy Drug in Clinical Trial for Children with Uncontrolled Seizures (2014) UCSF.

128. Center Integrated Healthcare (2013) Marijuana.

129. Division of alcohol and drug abuse. ADA, Marijuana. 